\title{
Effect of Carbamazepine on the Serum Level of Thyrotropin-Releasing Hormone
}

\author{
Ume Kalsoom*, Niaz Ali
}

Department of Pharmacology, Institute of Basic Medical Sciences, Khyber Medical University Peshawar, Pakistan

Received: 19 March 2019

Revised: 20 April 2019

Accepted: 03 May 2019

\section{*Correspondence to: \\ Dr. Ume Kalsoom, \\ Email: umekalsoom.khattak@ gmail.com}

Copyright: (c) the author(s), publisher and licensee Medip Academy. This is an openaccess article distributed under the terms of the Creative Commons Attribution NonCommercial License, which permits unrestricted noncommercial use, distribution, and reproduction in any medium, provided the original work is properly cited.

\begin{abstract}
Background: The thyroid gland is endocrine gland located in front and lower side of neck. Thyroid gland secretes two types of thyroid hormones that are triiodothyronine (T3) and tetraiodothyronine (T4). The hypothalamus is a center for regulation of thyroid hormones. It senses the low hormone levels and in turn releases thyrotropin-releasing hormone (TRH). TRH stimulates anterior pituitary to release TSH which then acts on the thyroid gland to maintain normal level of T3 and T4. The objective of study is to determine the effects of carbamazepine on TRH in euthyroid rabbits.

Methods: An experimental study performed on 30 rabbits. These were divided into three groups having 10 rabbits in each group. 10 rabbits were treated with $10 \mathrm{mg} / \mathrm{kg} /$ day of CBZ (OD), other 10 with $35 \mathrm{mg} / \mathrm{kg} /$ day CBZ (three divided doses) and 10 rabbits served as control. T3, FT4, TSH and TRH levels were evaluated at baseline and after 21 days of treatment in all three groups by Electrochemiluminescence immunoassay and ELISA respectively.

Results: Comparison of the hormone levels of the control group and the group having a dose of $10 \mathrm{mg} / \mathrm{kg} / \mathrm{day}$ for 21 day of treatment. Comparative results showed serum level of T3 $(\mathrm{P}=0.031)$, FT4 $(\mathrm{P}=0.030)$, and TRH $(\mathrm{P}=0.044)$ levels significantly lower than the control group and $\mathrm{TSH}(\mathrm{P}=0.057)$ levels remain unaltered. It was also found that group having a dose of $35 \mathrm{mg} / \mathrm{kg} / \mathrm{day}$; TDS showed decrease in T3 (P value 0.001), FT4 ( $\mathrm{P}=0.001)$, TSH $(\mathrm{P}=0.003)$ and TRH $(\mathrm{P}=0.001)$ level as compared to control group.

Conclusions: Our data suggest that Carbamazepine monotherapy does alter thyroid hormones and its central regulatory hormone TRH. Decrease in TRH level increase level of depression and suicidal thoughts and also risk of tertiary hypothyroidism. These findings could have very important clinical implications.
\end{abstract}

Keywords: Carbamazepine, FT4, T3, Thyroid gland, Thyrotropin-Releasing Hormone, TSH

\section{INTRODUCTION}

The thyroid gland is an endocrine gland located in front and lower side of neck. Thyroid gland secretes two types of thyroid hormones that are triiodothyronine (T3) and tetraiodothyronine (T4). Hypothalamus is center for regulation of thyroid hormones. It senses the low hormones level and in turn releases thyrotropin-releasing hormone (TRH). Thyrotropin-releasing hormone stimulates anterior pituitary to release thyroid stimulating hormone (TSH) which then acts on the thyroid gland to maintain normal level of T3 and T4. ${ }^{1}$ Normal level of the thyroid hormones in euthyroid adult are T3. (Triiodothyronine) total (0.8-2.1 $\mathrm{ng} / \mathrm{ml}), \quad \mathrm{T} 3$ (Triiodothyronine) free (3.4-7.2 pmol/1), T4 (thyroxine) total (42-120 ng/ml), T4 (thyroxine) free (11-24 pmol/l), TSH (Thyroid stimulating hormone) 0.5-8.9 $\mu \mathrm{lU} / \mathrm{ml}^{2}$ Euthyroid is a condition of thyroid gland when it is 
functioning normally. Less amount of thyroid hormone than the normal is called hypothyroidism, contrary to this if levels of thyroid hormones are increased then it is called hyperthyroidism. ${ }^{3}$ Causes of the hypothyroidism are many like thyroid gland autoimmune diseases (Atrophic thyroiditis, Postpartum thyroiditis, Hashimoto's thyroiditis), thyroid surgery, iodine abnormality, different drugs like lithium, amiodarone, Phenytoin, carbamazepine, interferon, interleukins and some drugs use in cancer chemotherapy (sunitinib, imatinib). ${ }^{4,5}$ Hyperthyroidism is caused by inflammatory conditions of the thyroid gland, tumor (benign) of thyroid or pituitary gland, large amount of tetraiodothyronine and iodine intake. $^{6}$ During 1993 new antiepileptic drugs were introduced into the market, which included Levetiracetam, oxcarbazepine, felbamate, tiagabine, gabapentin, lamotrigine, topiramate, and zonisamide. The old antiepileptic drugs include carbamazepine, phenobarbital, phenytoin, ethosuximide, valproate, and primidone. A reason behind the development of the new antiepileptic drugs is to avoid all the health related problems which arise from the use of the antiepileptic drugs, like gingival hyperplasia with phenytoin, osteoporosis with carbamazepine, and endocrine functional abnormality with lamotrigine, valporate, and carbamazepine. ${ }^{7}$ Carbamazepine was included in the therapeutic regimen for epilepsy during the 1960s and 1970s together with valproic acid and benzodiazepines. ${ }^{8}$

Carbamazepine is used for epilepsy (generalized seizures, mixed seizures, complex partial seizures), pain syndromes (paroxysmal extreme pain disorder, complex regional pain syndrome), Trigeminal neuralgia, Diabetes insipidus, Attention deficit hyperactivity disorder (ADHD), Phantom limb syndrome, Schizophrenia, post-traumatic stress disorder (post Cerebrovascular accident thalamic pain) and Neuromyotonia. ${ }^{9,10}$

Carbamazepine decreases the testosterone level in serum and decreases the free androgen indexes. Serum sex hormone binding globulin level increases because of carbamazepine use. ${ }^{11}$

Antiepileptic drugs and epilepsy both induce change in the hormonal system. The main interaction of antiepileptic drugs with thyroid, gonadal and adrenal gland is of much importance.

As it was established that the antiepileptic drugs act on voltage gated calcium and sodium channel. It also decreases the glutamenergic transmission and increases the gabanerigic transmission. The scientists expected that the similar mechanism is involved in the interaction of antiepileptic drugs with the hypothalamic hormones such as TRH, gonadotropin-releasing hormone (GnRH), growth hormone-releasing hormone (GHRH), and corticotropinreleasing hormone $(\mathrm{CRH})$. One possible mechanism in which hormones is affected is via stimulation and inhibition of the enzymes by these drugs. The effect of the drugs on the hypothalamic-pituitary-gonadal axis depends upon the sex of the patient. Such as in the male valproate increases the dehydroepiandrosterone sulfate and decreases the luteinizing and follicle-stimulating hormone levels. Increases the levels of testosterone and decreases the estradiol release and follicle stimulating hormone levels by valproate in females. Monotherapy of valproate has no effect on the T4 level but if combined with carbamazepine it decreases the T4 level and having no effect on the TSH. The enzymes induction property of the phenytoin, primidone, Phenobarbital decrease the bounded thyroxine level. Newer antiepileptic drugs like vigabatrin, tiagabine, lamotrigine, and levetiracetam have an effect on the thyroid hormones. Insulin and leptin levels increased in the case of valproate use, results in increase in the body weight. An opposite effect was shown by topiramate. Very less data is present regarding antiepileptic dugs effects on HPA axis as compared to its effects on thyroid, gonadal hormones. $^{12}$

Decline in the levels of T3, free T4 and T4 occurs after treatment with the carbamazepine. Increase in the serum thyrotropin occurs. Over all the carbamazepine has an effect on the hypothalamic-pituitary- thyroid axis. ${ }^{13}$

\section{METHODS}

This experiment was performed in the Institute of Basic Medical Sciences (IBMS), Khyber Medical University, Peshawar Animals House. This study was approved in the $29^{\text {th }}$ meeting of KMU-AS and RB under the reference no KMU-AS \&RB (Advance studies \& Research Board). This study was performed with the approval of Ethical Committee of Khyber Medical University, Peshawar under reference number DIR/KMU-EB/EC/000207.

Duration of the study was 1 year.

\section{Inclusion criteria}

Euthyroid rabbits having 1.5 to $2.5 \mathrm{kgs}$ body weight.

\section{Exclusion criteria}

- Animals which are pregnant.

- Animals which are in diseased state.

- Animals which are not euthyroid.

Rabbits were divided into 3 groups; each group contained 10 animals. The groups were treated according to the following plan.

\section{Group 1}

Normal control.

\section{Group 2}

Minimum recommended dose of carbamazepine (10 $\mathrm{mg} / \mathrm{kg} /$ day) OD for 21 days. 


\section{Group 3}

Maximum recommended dose of carbamazepine (35 $\mathrm{mg} / \mathrm{kg} /$ day) was given in three divided doses for 21 days. ${ }^{14,15}$

Their hormones levels were checked on baseline and after treatment with drug as per schedule. Blood were collected from the marginal ear vein of rabbits. T3, free T4, TSH levels will be checked through ElectroChemiluminescence Immunoassay (ECLIA) and TRH by ELISA kit. ${ }^{16}$

\section{Procedure of TRH Assay}

Before using samples were brought to the room temperature. After thawing the samples were centrifuged. All reagents were placed at room temperature before use. All the liquid reagents were gently mixed before use. $50 \mu \mathrm{L}$ of prepared sample and standard was added to the wells. $50 \mu \mathrm{L}$ of Biotinylated Detection Ab working solution was added immediately to the well. The plate was covered with plate sealer and incubated at $37^{\circ} \mathrm{C}$ for 45 minutes. The plate was washed with the washing buffer three times. The solution was decanted from the well properly and inverted against absorbent paper. $100 \mu \mathrm{L}$ of diluted HRP conjugate was added to each well. Again, plate was covered with plate sealer and was incubated at $37^{\circ} \mathrm{C}$ for 30 minutes. Washing was repeated for five times. Completely the solution was decanted from the wells and the decanted liquid was discarded.90 $\mu \mathrm{L}$ chromogenic substrate was added to the each well. Plate was covered with a plate sealer at $37^{\circ} \mathrm{C}$ for 15 minutes. Plate was protected from the light. Plate was developed in the dark at room temperature for half an hour.50 $\mu \mathrm{L}$ of stop solution was added to the each well. The change in the color from blue to yellow was observed. After half an hour of stopping of reaction the plate was observed. The absorbance of each well was read at $450 \mathrm{~nm}$.

\section{Procedure of T3, FreeT4 and TSH Assay}

Analyzer was Cobas e 411, Disk base. Reagents inventory was maintained. First of all system reagents procell and clean cell were loaded in analyzer and their caps were opened. Inventory of the cups and the tips were maintained. System water was filled up to the 3 liter and $35 \mathrm{ml}$ of SysWash was added. Liquid waste was disposed of. Ready to use reagent in special cassette were placed in a rack. Calibrator and control were also loaded. Reagent scan was clicked and analyzer did complete reagents inventory. In daily hand on maintenance analyzer was sent into the sleep mode and any condensation in reagent compartment and system reagent area were checked and the sample reagent probe was cleaned. Samples were loaded into the specific rack. Workplace option was clicked on the screen, sample ID, rack no, position and test types were selected in the software. Start option was clicked and the samples were analyzed automatically and the results were displayed on the screen.

\section{Data analysis procedure}

Data was analyzed using graph pad prism 2006. Same tool was used for construction of graphs. ANOVA (Dunnett's test) at $95 \%$ of confidence level, $\mathrm{p} \leq 0.05$ was used.

\section{RESULTS}

Estimation of serum levels of thyroid hormones of normal control and carbamazepine treated groups of rabbits were done after 21 days.

The mean Thyrotropin-releasing hormone (TRH) level of Group I (Normal Control) was (154.53 \pm 8.30$)$, Group II (Dose: $10 \mathrm{mg} / \mathrm{kg} / \mathrm{day})$ was $(146.40 \pm 5.94)$ and Group III (Dose: $35 \mathrm{mg} / \mathrm{kg} /$ day) was $(140.31 \pm 8.26)$, data was analyzed having $\mathrm{P}$ value 0.001 .

\section{Dunnett's multiple comparisons test results}

- Group I was compared with Group II having P value of 0.044 , which is statistically significant

- Group I was compared with Group III having P value 0.001, which is statistically significant (Figure A)

Mean Thyroid Stimulating hormone level of Group I (Normal Control) was (0.04 \pm 0.006$)$, Group II (Dose: 10 $\mathrm{mg} / \mathrm{kg} / \mathrm{day})$ was $(0.03 \pm 0.04)$ and Group III (Dose: 35 $\mathrm{mg} / \mathrm{kg} / \mathrm{day})$ was $(0.03 \pm 0.006)$, data was analysed having $\mathrm{P}$ value 0.005 .

\section{Dunnett's multiple comparisons test results}

- Group I was compared with Group II having P value of 0.057 , which is statistically significant

- Group I was compared with Group III having P value 0.003, which is statistically significant (Figure B)

Mean Triiodothyronine level of Group I (Normal Control) was (1.52 \pm 0.22 ), Group II (Dose: $10 \mathrm{mg} / \mathrm{kg} / \mathrm{day}$ ) was $(1.15 \pm 0.21)$ and Group III (Dose: $35 \mathrm{mg} / \mathrm{kg} /$ day) was $(0.96 \pm 0.47)$, data was analysed having $\mathrm{P}$ value 0.002 .

\section{Dunnett's multiple comparisons test results}

- Group I was compared with Group II having P value of 0.031 , which is statistically significant

- Group I was compared with Group III having P value 0.001, which is statistically significant (Figure C)

Mean Free Thyroxine level of Group I (Normal Control) was (10.48 \pm 1.67 ), Group II (Dose: $10 \mathrm{mg} / \mathrm{kg} /$ day) was $(8.06 \pm 2.74)$ and Group III (Dose: $35 \mathrm{mg} / \mathrm{kg} / \mathrm{day}$ ) was $(6.55 \pm 1.74)$. Data was analysed having $P$ value 0.001 .

\section{Dunnett's multiple comparisons test results}

- Group I was compared with Group II having P value of 0.030 , which is statistically significant 
- Group I was compared with Group III having P value 0.001 , which is statistically significant (Figure D)

(Table 1).

Table 1: Groups with respective hormones levels. (Mean $\pm S D, n=10)$ P values.

\begin{tabular}{|lllllll|}
\hline $\begin{array}{l}\text { Hormones } \\
\text { Levels }\end{array}$ & $\begin{array}{l}\text { Group I } \\
\text { (Normal } \\
\text { Control) }\end{array}$ & $\begin{array}{l}\text { Group II } \\
(\mathbf{1 0 m g} / \mathrm{kg} / \text { day })\end{array}$ & $\begin{array}{l}\text { Group III } \\
(\mathbf{3 5 m g / k g} / \mathbf{d a y})\end{array}$ & P Value & $\begin{array}{l}\text { Group I } \\
\text { vs. } \\
\text { Group II } \\
\text { (P value) }\end{array}$ & $\begin{array}{l}\text { Group I } \\
\text { vs. } \\
\text { Group III } \\
\text { (P Value) }\end{array}$ \\
\hline TRH $(\mathrm{pg} / \mathrm{ml})$ & $154.53 \pm 8.30$ & $146.40 \pm 5.94$ & $140.31 \pm 8.26$ & 0.001 & 0.044 & 0.001 \\
\hline TSH $(\mu \mathrm{IU} / \mathrm{ml})$ & $0.04 \pm 0.006$ & $0.03 \pm 0.007$ & $0.03 \pm 0.006$ & 0.005 & 0.057 & 0.003 \\
\hline T3 $(\mathrm{nmol} / \mathrm{l})$ & $1.52 \pm 0.22$ & $1.15 \pm 0.21$ & $0.96 \pm 0.47$ & 0.002 & 0.031 & 0.001 \\
\hline FT4 $(\mathrm{pmol} / \mathrm{l})$ & $10.48 \pm 1.67$ & $8.06 \pm 2.74$ & $6.55 \pm 1.74$ & 0.001 & 0.030 & 0.001 \\
\hline
\end{tabular}

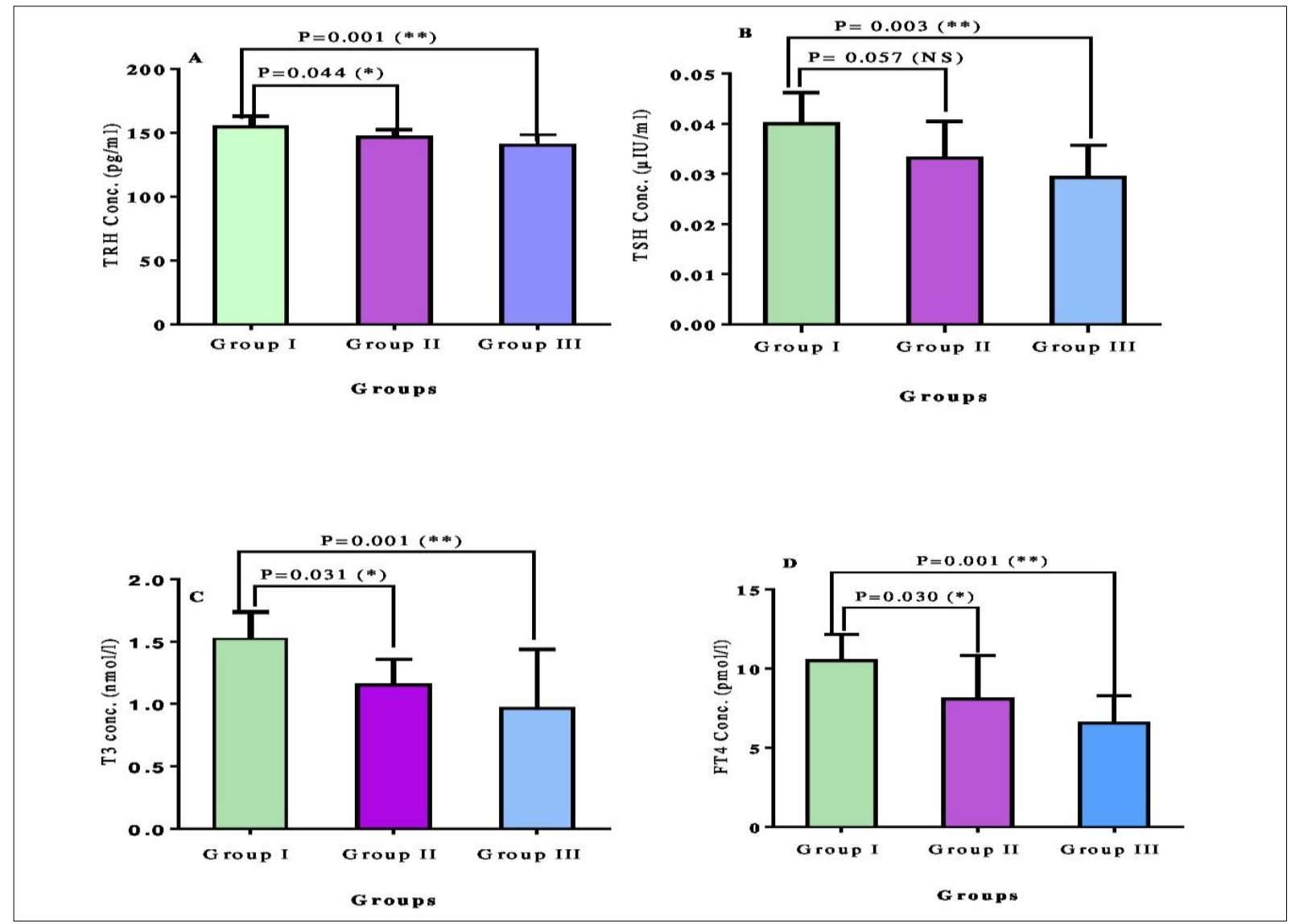

Figure 1: Graphical Representation of TRH, TSH, T3 and T4 Levels of Animals Groups. A) Comparative Graphical Representation of TRH Levels of Group I (Control), Group II (Dose.10mg/kg/day) and Group III (Dose.

$35 \mathrm{mg} / \mathrm{kg} / \mathrm{day}$ ), B) Comparative Graphical Representation of TSH Levels of Group I (Control), Group II

(Dose.10mg/kg/day) and Group III (Dose. 35mg/kg/day), C) Comparative Graphical Representation of

Triiodothyronine Levels of Group I (Control), Group II (Dose.10mg/kg/day) and Group III (Dose. 35mg/kg/day), D) Comparative Graphical Representation of free T4 Levels of Group I (Control), Group II (Dose.10mg/kg/day) and Group III (Dose. 35mg/kg/day).

\section{DISCUSSION}

This study focuses on the possible effects of carbamazepine on thyrotropin releasing hormone and other thyroid hormones related to its regulation.
As there are reports of subclinical signs of hypothyroidism with carbamazepine therapy with no significant effect on TSH and TRH levels. ${ }^{17}$ However, the final judgment is controversial regarding the possible inhibition on TRH level, which may be attributed to tertiary or central 
hypothyroidism. Though studies have shown that there are no significant change in TSH level, decrease in FT4 level and T3 level, yet a comprehensive and controlled model was necessary to answer the possible effect of carbamazepine on TRH level. ${ }^{18-23}$

Our results show a decrease in the T3 level similar to study done by Jouko I T Isojairvi et al. ${ }^{18}$ A decrease in the FT4 level is similarly to research done by JiriHoracek et al, Jouko I T Isojairvi et al, Kirimi E et al, Alberto Verrotti and his colleague, Aggarwal A and his co-workers. ${ }^{18,20-23}$ TSH level remains unaltered at $10 \mathrm{mg} / \mathrm{kg}$ dose similar to studies al- ready done by Jouko I $\mathrm{T}$ Isojairvi et al, Amirsalari- $\mathrm{S}$ and his co-worker and Kirimi E et al. ${ }^{18-20}$ TSH level decreases at maximum dose ( $35 \mathrm{mg} / \mathrm{kg} /$ day $)$ of carbamazepine, which is a new finding as compared to the old studies, which shows an increased or unaltered TSH level as compared to the control group. ${ }^{17-20,22,23}$ The least variation in the results as compared to old studies may be of difference in the doses, assay technique, environmental factors, and species variation. Level of TRH was decreased significantly after 21 days of treatment with maximum and minimum dose of carbamazepine. Induction of hepatic microsomal enzymes by carbamazepine increase the metabolism of the thyroid hormone (T3, FT4) is may be one of the reasons behind the decrease in the thyroid hormones level. ${ }^{24}$ TRH synthesis takes place in the neurons of the hypothalamus. It is transported from hypothalamus to median eminence presynaptic terminal region and store in synaptic vesicles. Release of the TRH contents from the synaptic vesicles takes place by depolarization. ${ }^{25}$ The release of the TRH depends upon the action potential firing and carbamazepine is the inhibitor of sodium and potassium channel. It was also investigated that carbamazepine blocks L-type calcium channel in rat hippocampal neurons. ${ }^{26-28}$ It may be possible that the inhibition of action potential decreases TRH secretion. TRH is responsible for the regulation of the prolactin and probably hyperprolactinemia is one of the side effects of the carbamazepine..$^{29,30}$ This may be the reason behind the decrease in TRH level after carbamazepine therapy.

The basic mechanism involved in the thyroid feedback mechanism is the conversion of the circulating $\mathrm{T} 4$ to $\mathrm{T} 3$ in the tanycytes and Astrocyte. ${ }^{31} \mathrm{~T} 3$ is transported in to the PVN by MCT8(A protein transporter, transport various iodothyronines). T3 cause the regulation of TRH at periventricularnuclei, by first formation of prepro-TRH transcript and processing of that transcript into mature TRH peptides. ${ }^{32}$

5 'D-II is one of the enzymes responsible for the conversion of T4 in to biological active T3. Carbamazepine enhances the activity of $5^{\prime} \mathrm{D}$-IIenzyme in experimental animals. ${ }^{33} \mathrm{It}$ leads to increase T3 concentration in different regions of brain including hypothalamus. A finding of the study shows that increased in the amount of $\mathrm{T} 3$ at the hypothalamus level decreased the pro-TRH significantly. ${ }^{34}$ It may be the possible inhibitory effect of Carbamazepine on TRH synthesis (Figure 2).

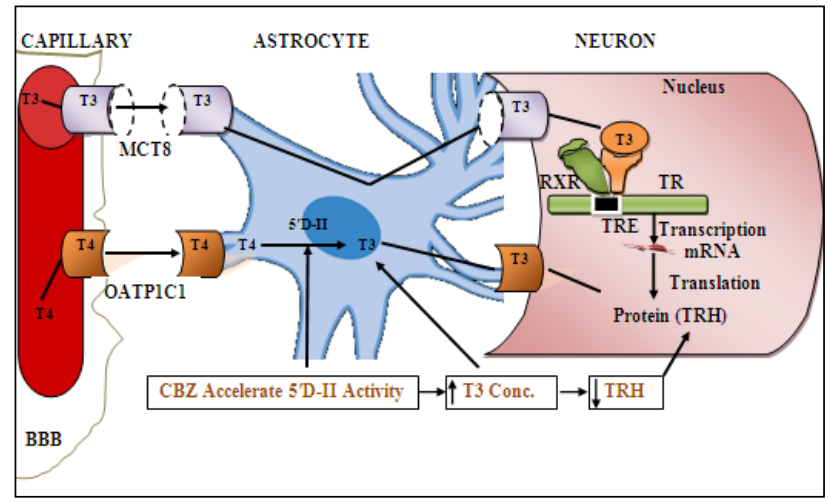

Figure 2: Regulation of TRH synthesis at hypothalamus level and possible inhibitory effect of CBZ. ${ }^{35}$

Reduction in the thyroid hormones leads to hypothyroidism. In the primary hypothyroidism, there is a decrease in the thyroid hormones because of an abnormal condition of the thyroid gland. ${ }^{36}$ In central hypothyroidism, there is a decrease in the normal functioning thyroid gland hormones because of insufficient stimulation of the thyroid gland by pituitary $\mathrm{TSH}$. There may be defects in the pituitary gland, which is called as secondary hypothyroidism. There may be the dysfunction of the hypothalamus, which is called as tertiary hypothyroidism. Disease of pituitary or hypothalamus causes central hypothyroidism. The decrease or normal level of FT4 and normal, slightly increased or disproportionately low thyroid stimulating hormones is used to diagnose central hypothyroidism (Figure 3). ${ }^{37}$

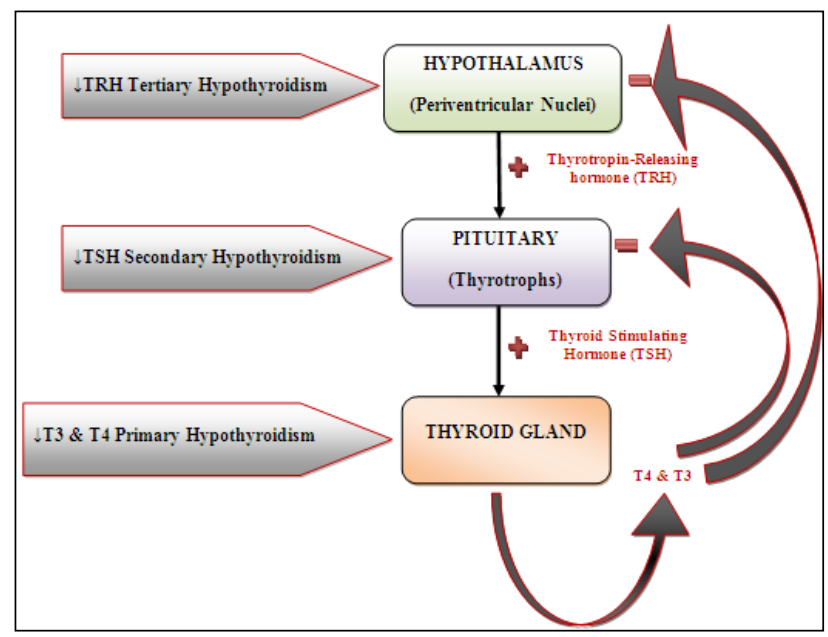

Figure 3: Hypothalamic-pituitary-thyroid axis. ${ }^{38}$

Studies have shown that the carbamazepine is involved in the reversible hypothyroidism. ${ }^{39}$ TRH has antidepressant property and use as a therapy for the patient suffering from unipolar depression. ${ }^{40}$ Besides, the study demonstrates the significant decrease in T3 and FT4 levels which are already studied may be attributed to the central effects of carbamazepine which causes tertiary hypothyroidism. A 
current research found out that carbamazepine decreases the serum level of TSH (at maximum recommended dose of CBZ) and TRH (at minimum and maximum recommended dose of CBZ) significantly, which exhibits that the drug has an inhibitory effect on the hypothalamus and may be involved in the central hypothyroidism so precautionary measure should be taken in order to prescribe this drug for the patients already suffering from hypothyroidism and depression and require antiepileptic therapy with carbamazepine. An alternative therapy may be opted rather than to produce another disease in shape of an iatrogenic hypothyroidism and to avoid suicidal thoughts in the patients.

\section{CONCLUSION}

Carbamazepine decreased the level of T3, FT4 and TRH at maximum and minimum recommended dose of carbamazepine. TSH level remain unaltered at $10 \mathrm{mg} / \mathrm{kg}$ dose but decreased at $35 \mathrm{mg} / \mathrm{kg}$. The results show that carbamazepine has an inhibitory effect on level of hypothalamus.

It needs further molecular level study to find out what is the main mechanism involved at the hypothalamus level to reduce TRH concentration by carbamazepine.

\section{Funding: No funding sources}

Conflict of interest: None declared

Ethical approval: The study was approved by the Institutional Ethics Committee of Khyber Medical University, Peshawar, Pakistan (DIR/KMUEB/EC/000207)

\section{REFERENCES}

1. Zoeller RT, Tan SW, Tyl RW. General background on the hypothalamic-pituitary-thyroid (HPT) axis. Crit Rev Toxicol. 2007 Jan-Feb;37(1-2):11-53.

2. Ciloglu F, Peker I, Pehlivan A, Karacabey K, Ilhan N, Saygin O, et al. Exercise intensity and its effects on thyroid hormones. Neuro Endocrinol Lett. 2005 Dec;26(6):830-4.

3. Singer PA, Cooper DS, Levy EG, Ladenson PW, Braverman LE, Daniels G, et al. Treatment guidelines for patients with hyperthyroidism and hypothyroidism. Standards of Care Committee, American Thyroid Association. JAMA. 1995 Mar 8;273(10):808-12.

4. Hussain Z, Elahi S. Undetected hypothyroidism and its anesthetic implications. Anaesth Pain Intensive Care. 2012;16(2):205-10.

5. Desai J, Yassa L, Marqusee E, George S, Frates MC, Chen $\mathrm{MH}$, et al. Hypothyroidism after sunitinib treatment for patients with gastrointestinal stromal tumors. Ann Intern Med. 2006 Nov 7;145(9):660-4.

6. Bahn Chair RS, Burch HB, Cooper DS, Garber JR, Greenlee MC, Klein I, et al. Hyperthyroidism and other causes of thyrotoxicosis: management guidelines of the American Thyroid Association and American
Association of Clinical Endocrinologists. Thyroid. 2011 Jun;21(6):593-646.

7. Pack, A. Effects of treatment on endocrine function in patients with epilepsy. Current treatment options in neurol. 2005;7(4):273-280.

8. Brodie MJ, Mintzer S, Pack AM, Gidal BE, Vecht CJ, Schmidt D. Enzyme induction with antiepileptic drugs: cause for concern? Epilepsia. 2013;54(1):1127.

9. Tolou-Ghamari Z, Zare M, Habibabadi JM, Najafi MR. A quick review of carbamazepine pharmacokinetics in epilepsy from 1953 to 2012. J Res Med Sci. 2013;18(Suppl 1):S81-S85.

10. Okuma T, Kishimoto A. A history of investigation on the mood stabilizing effect of carbamazepine in Japan. Psychiatry clin neurosci. 1998;52(1):3-12.

11. Löfgren E, Tapanainen JS, Koivunen R, Pakarinen A, Isojärvi JI. Effects of carbamazepine and oxcarbazepine on the reproductive endocrine function in women with epilepsy. Epilepsia. 2006;47(9):14416.

12. Leśkiewicz M, Budziszewska B, Lasoń W. Endocrine effects of antiepileptic drugs. Przegl Lek. 2007;65(11):795-8.

13. Bongu D, Sachdev J, Kabadi UM. Effects of carbamazepine on the hypothalamic-pituitary-thyroid axis. Endocr Pract.1999;5(5):239-244.

14. Scott A, Waldman AT. Pharmacology and Therapeutics Principal to practice. Elsevier Inc. $1^{\text {st }}$ Ed. 2008:1378.

15. Connell JM, Rapeport WG, Gordon S, Brodie MJ. Changes in circulating thyroid hormones during shortterm hepatic enzyme induction with carbamazepine. European J Clin Pharmacol. 1984;26(4):453-6.

16. Kaur RJ, Mehta B, Ambwani SR, Gehlot A. Effect of calcium channel blockers on the serum levels of thyroid hormone. Int $\mathrm{J}$ Basic Clin Pharmacol. 2013;2(4):476-9.

17. Verrotti A, Basciani F, Morresi S, Morgese G, Chiarelli F. Thyroid hormones in epileptic children receiving carbamazepine and valproic acid. Pediatr Neurol. 2001;25(1):43-6.

18. Isojärvi JI, Airaksinen KE, Repo M, Pakarinen AJ, Salmela P, Myllylä VV. Carbamazepine, serum thyroid hormones and myocardial function in epileptic patients. J Neurol Neurosur Psychiatry. 1993;56(6):710-2.

19. Amirsalari S, Dost ZT, Kavemanesh Z, Torkaman M, Beiraghdar F, Afsharpayman S, et al. Thyroid function in epileptic children who receive carbamazepine, primidone, phenobarbital and valproic acid. Iranian Journal of Child Neurology. 2011;5(2):17-22.

20. Kirimi E, Karasalihoğlu S, Boz A. Thyroid functions in children under long-term administration of antiepileptic drugs. Eastern J Med. 1999;4(1):23-6.

21. Simko J, Horacek J. Carbamazepine and risk of hypothyroidism: a prospective study. Acta Neurol Scand. 2007 Nov;116(5):317-21.

22. Verrotti A, Laus M, Scardapane A, Franzoni E, Chiarelli F. Thyroid hormones in children with 
epilepsy during long-term administration of carbamazepine and valproate. European J Endocrinol. 2009 Jan 1;160(1):81-6.

23. Aggarwal A, Rastogi N, Mittal H, Chillar N, Patil R. Thyroid hormone levels in children receiving carbamazepine or valproate. Pediatr Neurol. 2011 Sep 1;45(3):159-62.

24. Aanderud S, Myking OL, Strandjord RE. The influence of carbamazepine on thyroid hormones and thyroxine binding globulin in hypothyroid patients substituted with thyroxine. Clin Endocrinol. 1981 Sep;15(3):247-52.

25. Melmed S. The Pituitary. $3^{\text {rd }}$ Ed. USA:Elsevier Inc;2011.729.

26. Kwan P, Sills GJ, Brodie MJ. The mechanisms of action of commonly used antiepileptic drugs. Pharmacol Therapeut. 2001 Apr 1;90(1):21-34.

27. Bialer M, White HS. Key factors in the discovery and development of new antiepileptic drugs. Nat Rev Drug Discov. 2010;9(1):68-82.

28. Ambrósio AF, Soares-Da-Silva P, Carvalho CM, Carvalho AP. Mechanisms of action of carbamazepine and its derivatives, oxcarbazepine, BIA 2-093, and BIA 2-024. Neurochem Res. 2002 Feb;27(1-2):12130.

29. Evans GA, David DN, Rosenfeld MG. Regulation of prolactin and somatotropin mRNAs by thyroliberin. Proceedings of the National Academy of Sciences. 1978 Mar 1;75(3):1294-8.

30. Torre DL, Falorni A. Pharmacological causes of hyperprolactinemia. Ther Clin Risk Manag. 2007 Oct;3(5):929-51.

31. Karapanou O, Papadimitriou A. Thyroid hormone transporters in the human. Hormones. 2011 Oct 1;10(4):270-9.

32. hiamolera MI, Wondisford FE. Minireview: Thyrotropin-releasing hormone and the thyroid hormone feedback mechanism. Endocrinol. 2009 Mar;150(3):1091-6.

33. Baumgartner A, Pinna G, Hiedra L, Gaio U, Hessenius C, Campos-Barros A, et al. Effects of lithium and carbamazepine on thyroid hormone metabolism in rat brain. Neuropsychopharmacology. 1997 Jan;16(1):2541.

34. Mitsuma T, Hirooka Y, Yuasa K, Nogimori T. Effects of thyroid hormone, TRH and TSH on pro-TRH concentrations in various organs of rats. Endocrinol Exp. 1990 Dec;24(4):395-402.

35. Santos-Silva AP, Andrade MN, Pereira-Rodrigues $P$, Paiva-Melo FD, Soares P, Graceli JB, et al. Frontiers in endocrine disruption: Impacts of organotin on the hypothalamus-pituitary-thyroid axis. Mol Cell Endocrinol. 2018 Jan 15;460:246-57.

36. Chakera AJ, Pearce SH, Vaidya B. Treatment for primary hypothyroidism: current approaches and future possibilities. Drug Des Devel Ther. 2012;6:111.

37. Gupta V, Lee M. Central hypothyroidism. Indian J Endocrinol Metabolism. 2011 Jul;15(Suppl2):S99.

38. Hypothalamic-Pituitary-Thyroid Axis | Maitland Chiropractor - The Bolick Clinic of Chiropractic Wellness | Maitland Chiropractor - The Bolick Clinic of Chiropractic Wellness [Internet]. Bolickclinic.com. 2019. Available at: https://bolickclinic.com/hypothalamic-pituitarythyroid-axis/

39. Turan Mİ, Çayır A, Esin İS, Demir F, Tan H. The effects of carbamazepine on thyroid functions in childhood epilepsy. Dicle Med J/Dicle Tip Dergisi. 2013 Dec 1;40(4):533-6.

40. Luciano Martini, GMB. Clinical Neuroendocrinology, London: Academic Press, New York, San Francisco; 1977.

Cite this article as: Kalsoom U, Ali N. Effect of Carbamazepine on the Serum Level of ThyrotropinReleasing Hormone. Int J Basic Clin Pharmacol 2019;8:1349-55. 